\title{
A Dose Threshold for a Medium Transfer Bystander Effect for a Human Skin Cell Line
}

Zhengfeng Liou

McMaster University

Carmel Mothersill

McMaster University

Fiona McNeill

McMaster University School of Medicine

See next page for additional authors

Follow this and additional works at: https://arrow.tudublin.ie/radart

\section{Recommended Citation}

Liu, Z., Mothersill, C. \& McNeill, F. (2006). A dose threshold for a medium transfer bystander effect for a human skin cell line. Journal of Radiation Research.vol. 166, no. 1, pg. 19-23. doi:10.1667/RR3580.1.

This Article is brought to you for free and open access by the Radiation and Environmental Science Centre at ARROW@TU Dublin. It has been accepted for inclusion in Articles by an authorized administrator of ARROW@TU Dublin. For more information, please contact arrow.admin@tudublin.ie, aisling.coyne@tudublin.ie, gerard.connolly@tudublin.ie.

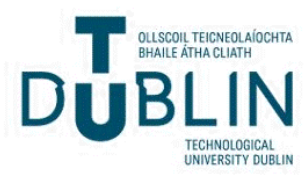




\section{Authors}

Zhengfeng Liou, Carmel Mothersill, Fiona McNeill, Fiona Lyng, Soo Hyun Byun, Colin Seymour, and William Prestwich 


\section{A dose threshold for a medium transfer bystander effect for a human skin cell line}

Zhengfeng Liu ${ }^{\mathrm{a}, 1}$, Carmel E. Mothersill ${ }^{\mathrm{a}}$, Fiona E. McNeill ${ }^{\mathrm{a}}$, Fiona M. Lyng ${ }^{\mathrm{b}}$, Soo Hyun Byun ${ }^{\mathrm{a}}$, Colin B. Seymour ${ }^{\mathrm{a}}$ and William V. Prestwich ${ }^{\mathrm{a}}$

${ }^{a}$ Medical Physics and Applied Radiation Sciences Department, McMaster University, 1280 Main Street West, Hamilton, ON, Canada L8S 4K1

${ }^{\mathrm{b}}$ Radiation and Environmental Science Centre, Dublin Institute of Technology, Dublin 8 , Ireland

1 figure, 2 tables:

Suggested running header: A dose threshold for a bystander effect

${ }^{1}$ Address for correspondence:

Zhengfeng Liu

Medical Physics and Applied Radiation Sciences Department, McMaster University, 1280 Main Street West, Hamilton, Ontario, Canada L8S 4K1;

Phone: (905) 525-9140 ext. 24499

Fax: (905) 522-5982

Email: liuz7@mcmaster.ca 
Liu, Z, Mothersill, CE, McNeill, FE, Lyng, FM., Byun, SH, Seymour, CB and Prestwich, WV. A dose threshold for a medium transfer bystander effect for a human skin cell line. Submitted Radiat. Res.

\begin{abstract}
The existence of radiation-induced bystander effects mediated by diffusible factors is now accepted but the mechanisms and precise behavior at low doses remain unclear. We exposed cells to gamma doses in the range $0.04 \mathrm{mGy}-5 \mathrm{~Gy}$, harvested the culture medium and transferred it to unirradiated reporter cells. Calcium fluxes and clonogenic survival were measured in the recipients. We show evidence for a dose threshold around $2 \mathrm{mGy}$ for the human skin cell line used with a suggestion of increased survival below that dose. Similar experiments using direct gamma irradiation showed no reduction in survival until the dose exceeded $7 \mathrm{mGy}$. Preliminary data for neutrons where the gamma dose was kept below the bystander threshold, does not show significant bystander effect in the dose range $1-33$ mGy. A lack of a bystander response with neutrons occurred at high dose around 1 Gy where significant cell killing from direct irradiation was observed. The result may have implications for understanding the role of bystander effects at low doses.
\end{abstract}




\section{INTRODUCTION}

Humans live in a radiation environment and are exposed to low levels of radiation through natural background, medical procedures and common items such as smoke detectors and televisions. Previously, most radiobiology experiments were carried out with relatively large doses of ionizing radiation and few data were available to estimate the biological effects of low doses. National and international committees use a linear non threshold relationship, extrapolated from high doses, for estimation of risk to health effects of ionizing radiation at low radiation doses. Low-dose radiation has no immediately noticeable effects on humans; nevertheless there is great interest in its longterm biological effects, which may include cancer in susceptible exposed individuals and genetic defects in their progeny. From recent data new concepts and paradigms have arisen which are likely to change established views in radiation protection. In particular, the new findings affect our views on low dose and low dose-rate effects.

Low doses of radiation cause bystander effects, i.e. damage occurs in cells that were not traversed by radiation but were in receipt of signals from irradiated cells (1-3). This is in contrast to the direct effect in which cells suffer interaction and show response. These effects challenge the validity of the simple linear extrapolation because the relationship between dose and effect is not simple. The detailed interaction between radiation and cells may help to rebuild the model in the low dose region and is therefore helpful for radiation protection as well as risk estimation (4).

Bystander effects have been well documented following both alpha and gamma irradiation of many cell lines (5-8). Neutrons provide another high LET radiation. Nevertheless, no information is available regarding neutron induction of the bystander 
effects. Such information is essential for a precise evaluation of the risks of environmental radiation and radiation therapy regimens. Neutron radiation is always contaminated by a contribution from gamma radiation. In order to differentiate the bystander effects from the two radiations, we need to know the dose threshold for induction of the bystander effects from gamma radiation. As long as we can keep gamma contamination below the threshold, the observed bystander effects should be caused solely by neutrons. In addition, we also need to investigate any possible beta dose due to activation of the cell medium, which will be exposed to neutron radiation.

There are mainly two kinds of studies of bystander effects: one indicates gap junctional intercellular communication in transmission of the signal $(7,9-10)$, the other is that medium from cells which have been exposed to gamma radiation can reduce the survival of unirradiated cells suggesting the existence of diffusible factors $(3,6)$. In this paper, the technique used was the medium transfer. The effect was monitored using measurements of intracellular calcium after exposure and we studied the colony forming ability of directly irradiated cells as well as cells receiving media harvested from irradiated cells (termed "bystander cells").

Previous studies show that bystander effects occur for a human skin keratinocyte (HPV-G) cell line over a $\gamma$ radiation dose range from $5 \mathrm{mGy}$ to 5 Gy (11-12). The dose rates of the previous studies were $18 \mathrm{~Gy} / \mathrm{hr}$ and $108 \mathrm{~Gy} / \mathrm{hr}$, respectively. In this paper we looked at very much lower gamma doses and at neutrons. Clonogenic survival and calcium flux measurements were used for the endpoints since they provide independent indicators of the bystander effect. An increase in the cytoplasmic calcium concentration is an early signal for initiation of apoptosis (13-14). Lyng et al. demonstrated the 
ratiometric measurement of calcium to monitor the bystander effect (15). This is a technique to investigate the ability of medium from irradiated cells to induce early events in the apoptosis.

\section{MATERIALS AND METHODS}

\section{Cell line and cell culture}

The HPV-G cell line has a well characterized and stable bystander response showing a reduction in cloning efficiency of $\sim 40 \%$ over a wide range of radiation doses and well characterized calcium fluxes and mitochondrial effects (15-17). This makes it ideal as a reporter system (18). All cell culture procedures were performed in a class II biosafety cabinet. The cell line was grown in DMEM/F12 medium containing $60 \mathrm{ml} \mathrm{FBS,}$ $5 \mathrm{ml}$ penicillin-streptomycin, $5 \mathrm{ml}$ L-Glutamine, $15 \mathrm{mM}$ HEPES buffer and $1 \mu \mathrm{g} / \mathrm{ml}$ hydrocortisone.

\section{Clonogenic assay technique and bystander protocol}

Flasks which were $85-90 \%$ confluent and that had received a medium change the previous day were chosen. Cells were removed from the flask using $0.25 \% \mathrm{w} / \mathrm{v}$ trypsin/ $1 \mathrm{mM}$ EDTA solution (1:1). When the cells had detached they were resuspended in medium, and an aliquot was counted using a Z2 Coulter Particle Count and Size Analyzer. Appropriate cell numbers $(\sim 300)$ were pipetted for plating in order to optimize the ratio of signal molecules to cell number. Cell survival was determined by using the clonogenic assay technique of Puck and Marcus (19). We irradiated at low cell density for the direct experiments so we could get colonies without trypsinising and replating the cells. Flasks

destined to donate medium were plated with around $5 \times 10^{5}$ per $5 \mathrm{ml}$ medium to give approximately 100,000 cells per $\mathrm{ml}$ in T25 40ml volume flasks (Nucleon, Denmark). 
Medium was harvested 1hour post irradiation, which took place $(6.0 \pm 0.2)$ hours after plating. The harvested medium was transferred to cultures containing cloning densities of cells set up at the same time as the donors. Controls for medium only and actual irradiation effects were included in each experiment. Controls for transfer of unirradiated medium from densely seeded cultures to cultures seeded at cloning densities were also always included. Cultures were incubated in $5 \mathrm{ml}$ of culture medium in $25 \mathrm{~cm}^{2}$, T25 40 $\mathrm{ml}$ flasks (Nunclon, Denmark), in a humidified $37^{\circ} \mathrm{C}$ incubator in an atmosphere of $5 \%$ $\mathrm{CO}_{2}$ in air.

\section{Irradiation}

The gamma sources used in this study were two ${ }^{60}$ Co sources. The dose rates of the two sources were $2.7 \mathrm{mGy} / \mathrm{hr}$ and $7.0 \mathrm{mGy} / \mathrm{hr}$, respectively. We used high dose dosimeter (loose chips) from Global Dosimetry Solutions Inc. to measure the dose rate. The chips were immersed in the cell growth media, which were in the flasks. The sourceto-flask distance was $10 \mathrm{~cm}$ and seven different doses covering from 0.04 to $7 \mathrm{mGy}$ were utilized to irradiate cells. The doses below $1 \mathrm{mGy}$ were given by the weak source (2.7 $\mathrm{mGy} / \mathrm{hr}$ ) and the other four doses were given by the $7 \mathrm{mGy} / \mathrm{hr}$ source.

Neutron irradiations were performed at the McMaster Accelerator Laboratory. The neutrons were produced by bombarding a thick lithium target with $2.30 \mathrm{MeV}$ protons in the laboratory's Van de Graff accelerators ( $\mathrm{KN}$ and Tandetron), inducing the ${ }^{7} \mathrm{Li}(\mathrm{p}, \mathrm{n})$ ${ }^{7} \mathrm{Be}$ reaction. This procedure produces a broad neutron spectrum extending to $600 \mathrm{keV}$ as described by Aslam et al. (20). The competing ${ }^{7} \mathrm{Li}$ (p, p') ${ }^{7} \mathrm{Li}$ reaction produces a 0.478 $\mathrm{MeV} \gamma$-ray which is also emitted in the $\beta^{-}$decay of ${ }^{7} \mathrm{Be}$. A $1.95 \mathrm{~cm}$ lead shield placed between the target and the irradiation position is used to attenuate these $\gamma$-rays. Irradiative 
capture of thermalised neutrons in surrounding material also produces a $\gamma$-ray field. The dose rates for $\mathrm{KN}$ accelerator (40 $\mathrm{cm}$ away from target) and Tandetron (10 $\mathrm{cm}$ away from target) were $(0.7 \pm 0.1) \mathrm{mGy} / \mathrm{min}$ and $(25 \pm 8) \mathrm{mGy} / \mathrm{min}$, respectively.

Microdosimetric methods were used to determine both neutron and $\gamma$-ray doses from the KN accelerator to which the cells were subjected. Dose measurements indicated the radiation field to be uniform over the region to be irradiated. The flasks containing the cells surrounded a $1.27 \mathrm{~cm}$ diameter spherical Rossi counter (Far West technology), so that the doses were monitored directly during the irradiation. The counter of the assembly was $40 \mathrm{~cm}$ from the target. Analysis of the pulse-height distribution revealed the gamma dose to be less than $3 \%$ of the neutron dose. Experiments were performed in which neutron doses in the range between 1 and 33 mGy were used to irradiate the cells. Measurements were made with the high dose dosimeters (loose chips) in contact with flasks and a liquid scintillator was used to assay any potential activity in the medium. Neither significant dose nor significant activity was observed.

One higher neutron dose was given to the cell cultures using the Tandetron accelerator due to the dose rate limitation of the $\mathrm{KN}$ accelerator. The cultures were about $10 \mathrm{~cm}$ from the target. The shielding geometry of Tandetron accelerator did not allow simultaneous dose measurements when the cell cultures were exposed to the neutron irradiation. This higher neutron dose radiation $(\sim 1$ Gy) was a very preliminary trial and doses were estimated based on the beam current setting of the accelerator.

For each dose, the experiments were repeated three times. In each experiment, each group (donor and directly irradiated) consisted of six flasks (three for unirradiated controls and three for irradiation). All the flasks were wrapped with Aluminum foil to 
protect cells from the exposure to light since phenol red in the culture can produce toxicity when exposed to light. This is a routine practice in our laboratory. The cultures were irradiated at room temperature. Cultures were returned to the incubator immediately after irradiation. Cells were irradiated $(6.0 \pm 0.2)$ hours after plating.

\section{Medium transfer}

This technique has been described in detail by Mothersill et al. (6). The previous results showed that contact times after irradiation from 30 minutes to 24 hours showed no significant difference on the toxicity of bystander medium to unirradiated cells (6). Briefly, medium was poured off from donor flasks which had been in the incubator one hour after irradiation. The medium was filtered through a $0.22 \mu \mathrm{m}$ filter used to filter out cells from the transferred medium. Culture medium was then removed from the flasks designated to receive irradiated medium. In each experiment, fourteen milliliters of the filtrate from the donor cells was immediately added to these recipient flasks without any washing. The remaining filtrate $(1 \mathrm{ml})$ was stored in a fridge for less than a month and then shipped to Dublin for calcium measurement, which was done blind with cell survival data.

\section{Ratiometric measurement of calcium}

Intracellular calcium levels were determined relative to control levels using two visible wavelength calcium sensitive dyes, Fluo 3 and Fura Red (Molecular Probes, Leiden). Fluo 3 exhibits an increase in green fluorescence upon binding to calcium whereas Fura Red exhibits a decrease in red fluorescence upon binding to calcium. The ratio Fluo 3 / Fura Red is a good indicator of intracellular calcium levels (21). HPV-G cells (approx. $1 \times 10^{5}$ ) were plated 24 hours prior to measurement into $35 \mathrm{~mm}$ Petri dishes 
with glass inserts (MatTek Corp, Ashland, MA). Cultures were washed twice with a buffer containing $130 \mathrm{mM} \mathrm{NaCl}, 5 \mathrm{mM} \mathrm{KCl}, 1 \mathrm{mM} \mathrm{Na}_{2} \mathrm{HPO}_{4}, 1 \mathrm{mM} \mathrm{CaCl}_{2}$ and $1 \mathrm{mM}$ $\mathrm{MgCl}_{2}$ (pH 7.4). Cells were loaded with the calcium sensitive dyes by incubation with 3 $\mu \mathrm{M}$ Fluo 3 and $3 \mu \mathrm{M}$ Fura Red AM esters for 1 hour in the buffer at $37^{\circ} \mathrm{C}$. Subsequently, the cultures were washed three times with buffer. Fluo 3 and Fura Red were excited at $488 \mathrm{~nm}$ and fluorescence emissions at $525 \mathrm{~nm}$ and $660 \mathrm{~nm}$ were recorded simultaneously using a Zeiss LSM 510 confocal microscope. Ratio images and time series data of the Fluo 3 / Fura Red fluorescence intensities were recorded every 2 seconds. Bystander medium was added after 60 seconds when a stable baseline had been established. For the analysis, a mean value from the fluorescence intensity values of approx. 50 individual cells was recorded. All measurements were performed at room temperature. The calcium ionophore A23187 (100 nM) was used a positive control to exclude experimental artefacts.

The intracellular calcium concentration was calculated using the fluorescence intensity of Fluo 3 according to the equation:

$$
[C a 2+]=K d *\left(\frac{f / f o}{(9-f / f o)}\right)
$$

where the value 9 was the dynamic range of Fluo 3. The dynamic range of an indicator is a measure of how much the fluorescence intensity changes upon binding of $\mathrm{Ca}^{2+} . \mathrm{Kd}$ was the apparent $\mathrm{Ca}^{2+}$-binding affinity of Fluo 3 determined in situ, $810 \mathrm{nM}$ and $\mathrm{f} / \mathrm{fo}$ was the relative change in Fluo 3 intensity (21).

\section{Incubation}


The two groups of cells (directly irradiated and recipients of bystander medium) were left untouched in the incubator for 10 days. Then, $10 \%$ formalin was used to fix the cells and the colonies were counted.

\section{RESULTS}

The experiments reported in this paper are designed to investigate the gamma threshold of bystander effect for HPV-G cell line. The plating efficiencies of the controlled groups for different doses are all around 20\%. Table 1 shows the survivals, corrected for the control plating efficiency, of the irradiated cells and the cells receiving bystander medium from different doses. No data were available for calcium measurement at the lowest three dose points because the samples were destroyed during the shipment from Hamilton, Canada to Dublin, Ireland. The relative survival curves for the two groups of cells also include the data from Refs. (11-12) and Mothersill (unpublished data). The clonogenic survivals for direct and bystander are shown in Figs. 1A and 1B, respectively.

$<$ Table 1>

$<$ Figure 1 $>$

Fig. 1A shows there is no direct cell killing at low dose rates $(<7 \mathrm{mGy} / \mathrm{hr})$ when the doses are less than $10 \mathrm{mGy}$. For the bystander effect, shown in Fig. 1B, the survival percentage at $3 \mathrm{mGy}$ is significantly less than $100 \%(\mathrm{p} \leq 0.005)$. Two plateaus are indicated in Fig. 1b: a solid line crossing 100\% indicates no cell killing at low dose region; a broken line crossing around $60 \%$ shows a stable cell survival from the bystander effect when the doses are beyond $300 \mathrm{mGy}$. 
Calcium signal measurements for the seven different gamma doses are shown in Table 1. The cell survival at $3 \mathrm{mGy}$ began to decrease from $100 \%$ at which point the calcium flux could be detected. As discussed in the introduction, the calcium results, therefore, are consistent with the cell data from the clonogenic survival experiments.

Based on the gamma radiation study of the bystander effect, we examined the bystander experiment caused by neutrons when the gamma doses were kept below $1 \mathrm{mGy}$, well below the observed gamma dose of 2 mGy threshold. The result in Table 2 shows there is no significant cell killing by either direct irradiation or transferred medium from irradiated cells when the doses are below $33 \mathrm{mGy}$. Meanwhile, no calcium fluxes were observed from the bystander medium at neutron doses $(7 \pm 1)$ and $(27 \pm 3) \mathrm{mGy}$. The data also shows a lack of a bystander response with neutrons at high dose (1.0 \pm 0.3$)$ Gy where significant cell killing occurs for direct neutron irradiation.

$<$ Table 2>

\section{DISCUSSION}

Bystander effects are well observed radiobiological phenomena in the low dose region. The aim of this paper was to see if there is a dose threshold for bystander effects and to perform a preliminary investigation of neutron effects. The gamma doses applied in this paper were below 10 mGy which can cause bystander effects and doses delivered at much lower rate than previous work. The clonogenic data in this paper indicates that there is no significant cell killing caused by direct gamma radiation or by the bystander effect when the doses are less than or equal to $2 \mathrm{mGy}$. Direct gamma radiation does not cause significant cell killing when the dose is less than $30 \mathrm{mGy}$. No bystander effect is

expected in the direct group. Previous studies showed that one requires around $2 \times 10^{5}$ 
cells to produce sufficient bystander signal $(3,6)$. We have investigated quantitatively the possibility that every cell within the exposed population will be irradiated at very low doses $(\sim 10 \mathrm{mGy})$. The frequency mean specific energy per event $\left(\bar{z}_{F}\right)$ for a $10 \mu \mathrm{m}$ site (diameter of HPV-G cell) irradiated by Cobalt-60 can be estimated as $0.56 \mathrm{mGy}$. An average single event specific energy $\left(\bar{z}_{F}\right)$ resulting in a certain dose (D) corresponds to an average number of events per site $N=D / \bar{z}_{F}$. The average number of events per site for a 10 mGy dose is 17.9. Based on the Poisson distribution, we can conclude that in a population of 300 cells the expected number not suffering an interaction is $5 \times 10^{-6}$ at 10 mGy, i.e. there is no bystander cell in the directly irradiated group.

The colony measurement is subject to some degree of statistical fluctuation. These inherent fluctuations represent an unavoidable uncertainty in this experiment, e.g. plating by using pipette. The experiments were repeated three times for each dose point to get better statistical results. The data were presented as mean \pm standard error. The final mean value was the weighted average of all the observations for each dose. The error analysis covers all the uncertainties in this study.

The data in Fig. 1 are from different dose rates (the maximum difference is in the order of $10^{4}$ ). This data involves the difficulties with giving low doses at high dose rate and vice versa. To achieve low dose ( $2 \mathrm{mGy}$ ) by using a high dose rate radiotherapy machine (18 Gy/hr), only 0.4 seconds are needed which is smaller than the transit time (0.6 second (11)). Mothersill and Seymour (12) reached the lowest dose (5 mGy) by increasing the source-to-flask distance to the maximum. The difficulty of high doses at low dose rate is limited by the exposure time of the cell cultures to room temperature. 
The direct radiation data, Fig. 1A, are discrete among different dose rate data. We have no explanation why the scatter in the direct effect data is greater than for the bystander data. Probably it is because of the oxidative stress induced by the direct irradiation which would vary from cell to cell depending on where the cell was hit and what response it was able to induce, but when the bystander medium was transferred to unirradiated cells, the same stress would induce a bystander factor in all the cells. The data indicate cell survival percentages from direct radiation may be dose rate dependent. This would contribute to increased scatter in the direct effect data. Bystander effect (medium transfer) data, however, show a smooth curve and do not indicate significant dose rate dependence. Furthermore, the bystander effect exists when the gamma dose is greater than and equal to $3 \mathrm{mGy}$. This result suggests there is a dose threshold for the bystander effects for the human skin cell line between 2 and $3 \mathrm{mGy}$. This conclusion is consistent with the calcium measurements, for which a signal is absent for doses at 1 and $2 \mathrm{mGy}$, but exists in the higher dose regions. Furthermore, the bystander effect observed at three different dose rates could be dose rate independent. In the very low dose region (microgray values), there is a suggestion of increased survival following exposure to both bystander signals and direct doses at the low dose range. The increased survivals for direct and bystander effects are not exactly at the same dose points. We are not yet in a position to postulate a mechanism.

Based on the results from the previous study and our experimental data, we for the first time report the results for the bystander effect caused by low dose neutron irradiations. In this case, no significant cell killing was observed either for the direct or bystander cases at doses below $33 \mathrm{mGy}$. For the low neutron doses used, the contribution 
from gamma rays is below the observed threshold between 2 and $3 \mathrm{mGy}$. The apparent lack of a bystander effect for the neutron irradiated cells is intriguing and unexpected. The difference between the results with gamma radiation and neutron radiation is an ongoing study, which we intend to pursue further. The observed result might contribute to a better understanding of radiation effects.

\section{ACKNOWLEDGMENTS}

We thank Dr. Douglas Boreham, McMaster University, for providing access to the utilities in his lab, Steve Staniek for radiation safety suggestions, and Scott McMaster and Jason Falladown for their assistance with dosimetry. We acknowledge funding from the Canada Research Chair Program.

\section{REFERENCES}

1. H. Nagasawa and J. B. Little, Induction of sister-chromatid exchanges by extremely low doses of alpha particles. Cancer Res., 52, 6394-6396 (1992)

2. A. Deshpande, E. H. Goodwin, S. M. Bailey, B. L. Marrone and B. E. Lehnert, Alpha-particle-induced sister chromatid exchange in normal human lung fibroblasts: evidence for an extranuclear target. Radiat. Res., 145, 260-267 (1996)

3. C. Mothersill and C. B. Seymour, Cell-cell contract during gamma irradiation is not required to induce a bystander effect in normal human keratinocytes: Evidence for release during irradiation of a signal controlling survival into the medium. Radiat. Res., 149, 256-262 (1998)

4. G. Schettino, M. Folkard, B. D. Michael and K. M. Prise, Low-dose Binary behavior of bystander cell killing after microbeam irradiation of a single cell with focused $\mathrm{C}_{\mathrm{k}} \mathrm{X}$ rays, Radiat. Res., 163, 332-336 (2005) 
5. S. A. Lorimore, M. A. Kadhim, D. A. Pocock, D. Papworth, D. L. Stevens, D. T. Goodhead and E. G. Wright, Chromosomal instability in the descendants of unirradiated surviving cells after $\alpha$-particle irradiation. Proc. Natl. Acad. Sci. US A., 95, 5730-5733 (1998)

6. C. Mothersill and C. B. Seymour, Medium from irradiated human epithelial cells but not human fibroblasts reduces the clonogenic survival of unirradiated cells. Int. J. Radiat. Biol. 71, 421-427 (1997)

7. E. I. Azzam, S. M. de Toledo, T. Gooding and J. B. Little, Intercellular communication is involved the bystander regulation of gene expression in human cells exposed to very low fluences of alpha particles. Radiat. Res., 150, 497-504 (1998)

8. K. M. Prise, O. V. Belyakov, M. Folkard and B. D. Michael, Studies of bystander effects in human fibroblasts using a charged particle microbeam. Int. J. Radiat. Biol. 74, 793-798 (1998)

9. E. I. Azzam, S. M. de Toledo, and J. B. Little, Direct evidence for the participation of gap junction-mediated intercellular communication in the transmission of damage signals from a-particle irradiated to nonirradiated cells. Proc. Natl. Acad. Sci. US A., 98, 473-478 (2001)

10. H. Nagasawa and J. B. Little, Unexpected sensitivity to the induction of mutations by very low doses of alpha particle radiation: evidence for a bystander effect. Radiat. Res. 152, 552-557 (1999) 
11. C.B Seymour and C.E. Mothersill, Relative contribution of bystander and targeted cell killing to the low dose region of the radiation dose response curve. Radiat. Res., 153, 508-511 (2000)

12. C. Mothersill and C. B. Seymour, Bystander and delayed effects after fractioned radiation exposure. Radiat. Res., 158, 626-633 (2002)

13. D. M. Ojcius, A. Zychlinsky, L. M. Zheng and J. D. Young, Ionophore-induced apoptosis: Role of DNA fragmentation and Calcium fluxes, Exp. Cell. Res. 197, 43-49 (1991)

14. D. E. Clapham, Calcium signaling, Cell, 80, 259-268 (1995)

15. F. M. Lyng, C. B. Seymour and C. E. Mothersill, Production of a signal by irradiated cells which leads to a response in unirradiated cells characteristic of initiation of apoptosis, Br. J. Cancer, 83, 1223-1230 (2000).

16. C. B. Seymour and C. E. Mothersill, Relative contribution bystander and targeted cell killing to the low dose region of the radiation dose-response curve. Radiat. Res., 153, 508-511 (2000)

17. F. M. Lyng, C. B. Seymour and C. Mothersill, Initiaiton of apoptosis in cells exposed to medium from the progeny of irradiated cells: a possible mechanism for bystander-induced genomic instability?, Radiat. Res., 157, 365-370 (2002)

18. C. Mothersill, D. Rea, E. G. Wright, S. A. Lorimore, D. Murphy, C. B. Seymour, and K. O'Malley, Individual variation in the production of a 'bystander signal' following irradiation of primary cultures of normal human urothelium, Carcinogenesis, 22, 1465-1471 (2001) 
19. T. T. Puck P. I. Marcus, Action of X-rays on mammalian cells. J. Exp. Med. 103, 653-666 (1956).

20. Aslam, W. V. Prestwich, F. E. McNeill and A. J. Waker, Development of a lowenergy monoenergetic neutron source for applications in low-dose radiobiological and radiochemical research. Appl. Radiat. Isot. 58, 629-642 (2003).

21. D. Thomas, S.C. Tovey, T.J. Collins, M.D. Bootman, M. J. Berridge, P. Lipp, A comparison of fluorescent $\mathrm{Ca} 2+$ indicator properties and their use in measuring elementary and global Ca2+ signals, Cell Calcium 28, 213-223 (2000) 


\section{FIGURE LEGENDS}

FIG. 1. (A) Clonogenic survivals for HPV-G cells exposed to gamma radiation (Direct). (B) clonogenic survivals for the cells receiving bystander medium harvested from irradiated cells (Bystander). The data have been normalized to $100 \%$ for both controls. The data of doses greater than 10 mGy are from Refs. (11-12) and Mothersill (unpublished data). The dose rate used in Ref. (11) and the unpublished data was 18 Gy/hr while the dose rate in Ref. (12) was $108 \mathrm{~Gy} / \mathrm{hr}$. Solid lines in Figs. 1A and B indicate $100 \%$ survival. The dotted line in Fig.1B indicates a surviving fraction plateau for the bystander effect when the doses are beyond $300 \mathrm{mGy}$. A 3 mGy cut-off refers to data shown in Table 1.

\section{FOOTNOTES}

1 Address for correspondence: Medical Physics and Applied Radiation Sciences Department, McMaster University, 1280 Main Street West, Hamilton, Ontario, Canada L8S 4K1;

Phone: (905) 525-9140 ext. 24499

Fax: (905) 522-5982

Email: liuz7@mcmaster.ca 
Table 1 Survival percentages for the irradiated and bystander cells $\mathrm{s}^{\mathrm{a}}$

\begin{tabular}{|c|c|c|c|c|c|c|c|c|c|c|}
\hline \multirow{2}{*}{$\begin{array}{l}\gamma \text { Dose } \\
(\mathrm{mGy})^{\mathrm{c}}\end{array}$} & \multicolumn{4}{|c|}{$\begin{array}{c}\text { Irradiation }^{\mathrm{b}} \\
\text { Survival percentages }(\%)^{\circ}\end{array}$} & \multicolumn{6}{|c|}{$\begin{array}{c}\text { Bystander }^{\mathrm{b}} \\
\text { Survival percentage }(\%)\end{array}$} \\
\hline & $1^{\mathrm{d}}$ & $2^{\mathrm{d}}$ & $3^{\mathrm{d}}$ & Mean & $1^{\mathrm{d}}$ & $2^{d}$ & $3^{d}$ & Mean & $\begin{array}{l}\text { Basal } \\
{\left[\mathrm{Ca}^{2+}\right]} \\
(\mathrm{nM})^{\mathrm{d}}\end{array}$ & $\begin{array}{c}\text { Peak } \\
{\left[\mathrm{Ca}^{2+}\right](\mathrm{nM})^{\mathrm{d}}}\end{array}$ \\
\hline 0.04 & $95 \pm 10$ & $91 \pm 11$ & $119 \pm 15$ & $98 \pm 7$ & $119 \pm 14$ & $117 \pm 13$ & $92 \pm 13$ & $109 \pm 8$ & $\mathrm{~N} / \mathrm{A}^{\mathrm{e}}$ & $\mathrm{N} / \mathrm{A}^{\mathrm{e}}$ \\
\hline 0.14 & $98 \pm 10$ & $117 \pm 12$ & $124 \pm 15$ & $110 \pm 7$ & $116 \pm 14$ & $125 \pm 14$ & $83 \pm 12$ & $108 \pm 7$ & $\mathrm{~N} / \mathrm{A}^{\mathrm{e}}$ & $\mathrm{N} / \mathrm{A}^{\mathrm{e}}$ \\
\hline 0.27 & $105 \pm 11$ & $117 \pm 12$ & $119 \pm 15$ & $112 \pm 7$ & $107 \pm 14$ & $105 \pm 12$ & $86 \pm 13$ & $98 \pm 7$ & $\mathrm{~N} / \mathrm{A}^{\mathrm{e}}$ & $\mathrm{N} / \mathrm{A}^{\mathrm{e}}$ \\
\hline 1.0 & $111 \pm 16$ & $106 \pm 6$ & $97 \pm 9$ & $104 \pm 4$ & $87 \pm 22$ & $103 \pm 6$ & $107 \pm 9$ & $104 \pm 5$ & $105 \pm 4$ & $113 \pm 1$ \\
\hline 2.0 & $86 \pm 14$ & $98 \pm 11$ & $96 \pm 6$ & $95 \pm 5$ & $81 \pm 21$ & $104 \pm 15$ & $104 \pm 10$ & $101 \pm 8$ & $110 \pm 7$ & $123 \pm 8$ \\
\hline 3.0 & $102 \pm 18$ & $100 \pm 11$ & $104 \pm 6$ & $103 \pm 5$ & $73 \pm 21$ & $108 \pm 15$ & $86 \pm 5$ & $87 \pm 5$ & $106 \pm 2$ & $257 \pm 1^{\mathrm{f}}$ \\
\hline 5.0 & $98 \pm 4$ & $91 \pm 3$ & $93 \pm 10$ & $94 \pm 2$ & $88 \pm 3$ & $95 \pm 3$ & $85 \pm 8$ & $91 \pm 2$ & $106 \pm 2$ & $248 \pm 1^{f}$ \\
\hline 7.0 & $119 \pm 14$ & $100 \pm 6$ & $88 \pm 7$ & $98 \pm 4$ & $73 \pm 12$ & $89 \pm 8$ & $80 \pm 7$ & $82 \pm 5$ & $103 \pm 2$ & $266 \pm 2^{f}$ \\
\hline
\end{tabular}

${ }^{a}$ Three repeat experiments were done for each dose point

${ }^{\mathrm{b}}$ For each group (direct and bystander), six flasks (three for unirradiated control and three for irradiation) per dose point were evaluated in each experiment

${ }^{\mathrm{c}}$ The estimated gamma dose uncertainty is $5 \%$

${ }^{\mathrm{d}}$ values are means $\pm \mathrm{SEM}, \mathrm{n}=3$

${ }^{e}$ No data were available for the three doses due to the destruction of the samples during the shipment from Hamilton to Dublin ${ }^{\mathrm{f}} \mathrm{p}<0.002$ 

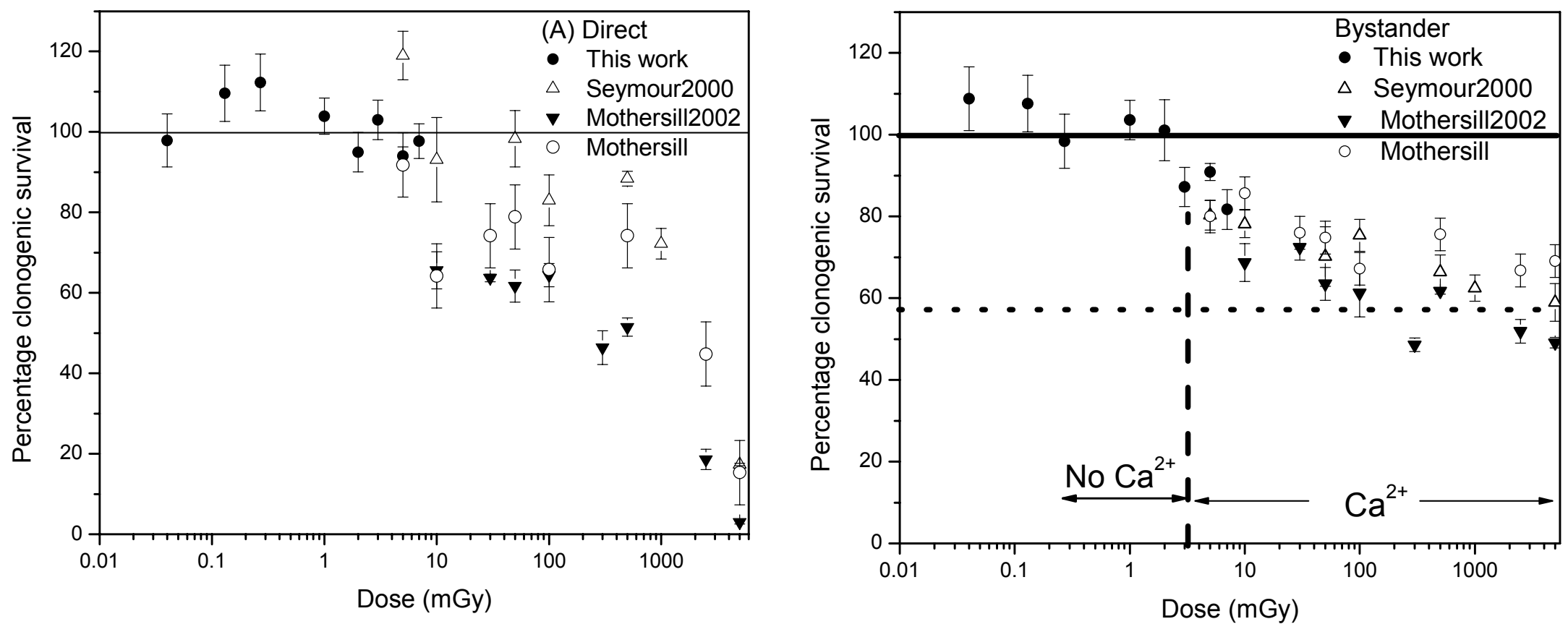

Fig. 1 (A) Clonogenic survivals for HPV-G cells exposed to gamma radiation (Direct). (B) clonogenic survivals for the cells receiving bystander medium harvested from irradiated cells (Bystander). The data have been normalized to 100\% for both controls. The data of doses greater than $10 \mathrm{mGy}$ are from Refs. (11-12) and Mothersill (unpublished data). The dose rate used in Ref. (11) and the unpublished data was $18 \mathrm{~Gy} / \mathrm{hr}$ while the dose rate in Ref (12) was $108 \mathrm{~Gy} / \mathrm{hr}$. Solid lines in Figs. 1A and B indicate 100\% survival. The dotted line in Fig.1B indicates a surviving fraction plateau for the bystander effect when the doses are beyond 300 mGy. A 3 mGy cut-off refers to data shown in Table 1. 
Table 2 Formed colony numbers and survival percentages for the neutron irradiated and bystander cells

\begin{tabular}{cccc}
\hline $\begin{array}{c}\text { Neutron Dose } \\
(\mathrm{mGy})\end{array}$ & $\begin{array}{c}\gamma \text { dose component } \\
(\mathrm{mGy})\end{array}$ & $\begin{array}{c}\text { Survival percent (\%) } \\
\text { Irradiation }\end{array}$ & Bystander \\
\hline $1.3 \pm 0.1$ & $0.040 \pm 0.004$ & $97 \pm 8$ & $101 \pm 8$ \\
$2.6 \pm 0.3$ & $0.080 \pm 0.008$ & $90 \pm 6$ & $107 \pm 4$ \\
$3.8 \pm 0.4$ & $0.11 \pm 0.01$ & $97 \pm 13$ & $105 \pm 5$ \\
$7 \pm 1$ & $0.20 \pm 0.02$ & $100 \pm 8$ & $85 \pm 7$ \\
$27 \pm 3$ & $0.80 \pm 0.08$ & $115 \pm 21$ & $96 \pm 12$ \\
$33 \pm 3$ & $1.0 \pm 0.1$ & $100 \pm 6$ & $105 \pm 6$ \\
$1000 \pm 300^{\text {a }}$ & $30 \pm 9^{\mathrm{a}}$ & $8 \pm 2$ & $111 \pm 11$ \\
\hline
\end{tabular}

${ }^{a}$ This neutron high dose radiation was a very preliminary trial and doses were estimated based on the beam current setting of the accelerator. 